\title{
ANALISIS PENERAPAN PENGGUNAAN GRAPHIC EDITOR PADA PEMBUATAN OBJEK 3 DIMENSI
}

\section{Nurcahyani Dewi Retnowati}

Teknik Informatika

Sekolah Tinggi Teknologi Adisutjipto

Jalan Janti Blok-R Lanud Adisutjipto Yogyakarta

yayayadewi@gmail.com

Abstract

Three-dimensional applications has evolved penetrated in almost all areas of work, especially in the field of multimedia and other virtual media. Of feature films, television, print design to production games. LightWave $3 D$ is a software that can model an object once animate. This research model a $3 D$ object using LightWave Modeler then analyzed the results of modeling using graphic editors in LightWave Layout. To connect between LightWave Modeler and LightWave Layout used LightWave Hub. Analysis using the graphic editor can make a better model for the selection of each layer more detail.

Keywords: LightWave 3D, LightWave Modeler, LightWave Layout, Graphic Editor

Abstrak

Aplikasi 3 dimensi telah berkembang merambah di hampir semua area kerja, terutama pada bidang multimedia dan media virtual lainnya. Dari film layar lebar, televisi, desain cetak sampai produksi games. LightWave 3D merupakan suatu peranti lunak yang dapat memodelkan suatu objek sekaligus menganimasikannya. Penelitian ini memodelkan suatu objek 3D dengan menggunakan LightWave Modeler kemudian dilakukan analisis hasil pemodelan dengan menggunakan graphic editor yang ada pada LightWave Layout. Untuk menghubungkan antara LightWave Modeler dan LightWave Layout digunakan LightWave Hub. Analisis dengan menggunakan graphic editor dapat membuat suatu pemodelan menjadi lebih baik karena penyeleksian setiap layer lebih detil.

Kata kunci: LightWave 3D, LightWave Modeler, LightWave Layout, Graphic Editor.

\section{Pendahuluan}

Dalam beberapa tahun belakangan ini, 3 dimensi telah berkembang di segala area kerja. Kita dapat merasakan pengaruhnya terutama di media-media virtual. Dari film layar lebar, televisi sampai produksi games. LightWave 3D sebagai salah satu software 3D terkemuka juga tidak ketinggalan ikut berkompetisi dalam bidang-bidang tersebut. Malah bukan hanya itu LightWave 3D bahkan merambah dunia printing. Banyak cover untuk majalah Time dan Newsweek yang dikerjakan dengan LightWave 3D 
Interface LightWave 3D memiliki ciri yang sangat berbeda dengan software-software 3D lainnya. LightWave 3D memiliki dua buah interface terpisah dengan kegunaan yang berbeda. Untuk keperluan modeling, pengguna harus menggunakan LightWave Modeler, sedangkan untuk keperluan animasi pengguna harus menggunakan LightWave Layout. LightWave Hub digunakan sebagai penghubung antara LightWave Modeler dengan LightWave Layout, sehingga dapat memudahkan ketika melakukan impor desain 3 dimensi. Desain yang telah dibuat di LightWave Modeler nantinya akan diimpor ke LightWave Layout jika membutuhkan pencahayaan dan rendering suatu objek 3 dimensi.

Pada pembuatan objek 3D dapat menggunakan tool-tool yang ada di dalam software, salah satunya dengan menggunakan graphic editor. Namun penggunaan graphic editor pada pembuatan objek 3D membutuhkan suatu analisis yang tepat sehingga dapat menghasilkan objek 3D yang lebih baik.

Oleh karena itu dalam penelitian ini akan dilakukan pembuatan objek tiga dimensi kemudian dianalisis menggunakan tool graphic editor.

\section{Landasan Teori}

\subsection{LightWave 3D}

LightWave 3D adalah software 3D yang memiliki kemampuan yang berimbang dengan software-software 3D lainnya. Hal ini dibuktikan dengan digunakannya LightWave oleh rumah produksi kelas dunia untuk mengerjakan berbagai keperluan, mulai dari printing (Time dan Newsweek), Game (mulai dari game console hingga game pada handphone), film layar kaca (Babylon 5, Firefly, Children of Dune) hingga film layar lebar (Jimmy Neutron, Boy Genius).

Dalam dunia 3D pada umumnya, modeling adalah proses menciptakan permukaan maupun bidang 3D secara virtual pada objek dan karakter rancangan desainer. Bagi para desainer 3D, proses modeling ini merupakan proses yang menjemukan dibanding proses lain, misalnya pencahayaan. Namun modeling memainkan peranan yang penting pada alur kerja (work flow) secara keseluruhan karena "benda-benda" hasil modeling merupakan kanvas saat pemberian material, tekstur, maupun cahaya. Semakin akurat modeling yang dikerjakan pada aspek ukuran, bentuk, detil dan proporsinya scene akhir akan semakin terlihat realistis.

Programmer dapat mengembangkan kemampuan LightWave dengan menggunakan SDK yang telah termasuk dan juga menggunakan bahasa "scripting" khusus disebut Lscript. SDK ini berdasarkan Bahasa $\mathrm{C}$ dan hampir semuanya dapat diciptakan, dari sebuah shader sendiri sampai ke pengekspor format pandangan yang berbeda. LightWave juga termasuk selusin plugin gratis dan banyak lagi lainnya yang dapat diperoleh dari beberapa pengembang yang berbeda di seluruh dunia.

LightWave merupakan aplikasi multi-threaded dan dapat menggunakan sebanyak 8 prosesor dalam mesin yang sama pada waktu yang sama ketika merender gambar.

Penjelasan tentang LightWove 3D dapat dilihat pada menu Help dalam aplikasi (seperti pada Gambar 1).

\section{Metode Penelitian}

Metode penelitian yang digunakan dalam penelitian ini adalah:

a. Metode Kepustakaan adalah cara pengumpulan data dengan mengumpulkan dokumen-dokumen tentang objek 3 dimensi 
b. Metode desain dan animasi objek 3 dimensi menggunakan software LightWave 3D. Desain dan animasi objek 3 dimensi meliputi pemodelan.

c. Metode analisis hasil dengan graphic editor. Setelah dilakukan pemodelan kemudian dilanjutkan dengan proses analisis desain dengan menggunakan graphic editor.

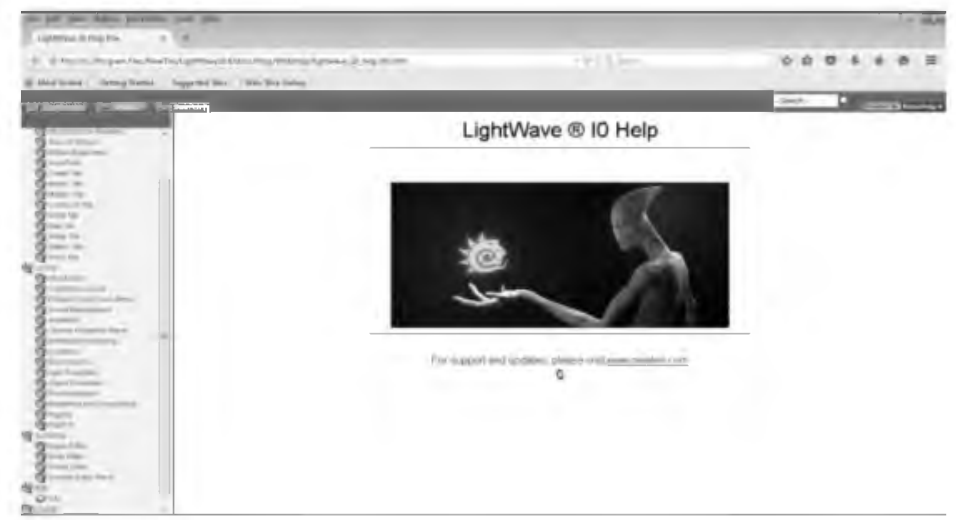

Gambar 1. F1 Menu Help pada LightWave 3D

\section{Hasil Dan Pembahasan}

\subsection{Spesifikasi Hardware dan Software}

Hardware dan software yang digunakan pada pembuatan desain dan animasi serta analisis hasil adalah sebagai berikut:

Hardware yang digunakan pada pembuatan desain dan animasi serta analisis hasil adalah sebagai berikut:

1. CPU: Intel Core i3

2. $R A M 2 G B$

3. $H D D 500 G B$

\section{Mouse dan Keyboard}

Software yang digunakan pada pembuatan desain dan animasi serta analisis hasil adalah sebagai berikut:

\section{OS Windows 7}

2. Software desain animasi Lightwave 3D 8.0

\subsection{Pemodelan (Modeling)}

Pemodelan (modeling) merupakan proses pembuatan scene 3D berupa objek, bisa dikatakan pemodelan dalam LightWave termasuk hal yang paling krusial, karena pemodelan adalah tahap awal sebelum melanjutkan ke proses pemberian material, pencahayaan, dan animasi. Pemodelan meliputi langkah-langkah membuat pesawat dengan menggunakan software LightWave.

Langkah-langkah membuat Pesawat dengan Menggunakan LightWave

1. Open LightWave (Modeler) 
Seperti terlihat pada Gambar 2 (Tampilan Folder NewTek), Gambar 3 (Tampilan LightWave Hub, Layout dan Modeler dalam folder NewTek) dan Gambar 4 (Tampilan Antarmuka LightWave Modeler).

2. Kemudian pilih selection Polygon mode (Gambar 5). Selection Mode ada tiga jenis antara lain Point Mode, Edge Mode dan Polygon Mode.

3. Setelah memilih jenis mode, kita dapat memilih Pen untuk mengambar Body Pesawat.

4. Setelah menggambar body pesawat, kemudian memberi ketebalan dengan menggunakan tool Extrude.

5. Supaya object body terlihat halus maka dapat digunakan tool Smooth Shift. Setelah memodeling body kemudian pindah ke layer baru untuk memodeling bagian pesawat yang lain seperti bagian wing, ekor pesawat dan kokpit pesawat. Contoh masing-masing bagian pesawat dapat dilihat pada Gambar 6 (body pesawat), Gambar 7 (sayap belakang horisontal), Gambar 8 (sayap belakang vertikal), Gambar 9 (sayap depan).

6. Kemudian bagian-bagian pesawat yang telah selesai di-modelling disatukan (Gambar 10).

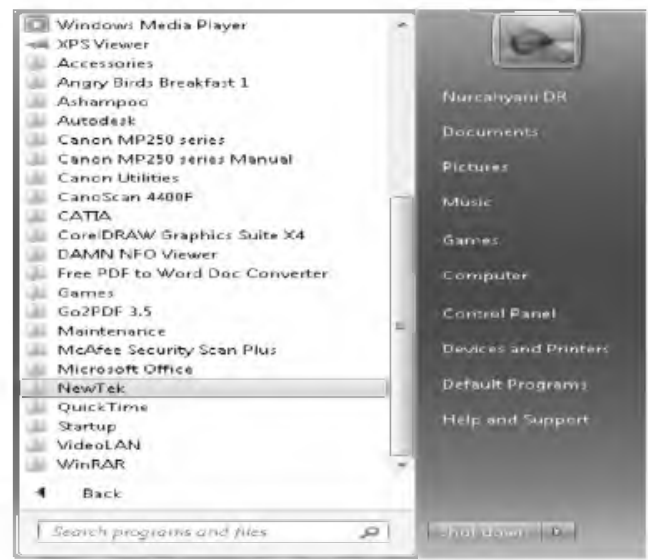

Gambar 2. Tampilan Folder NewTek

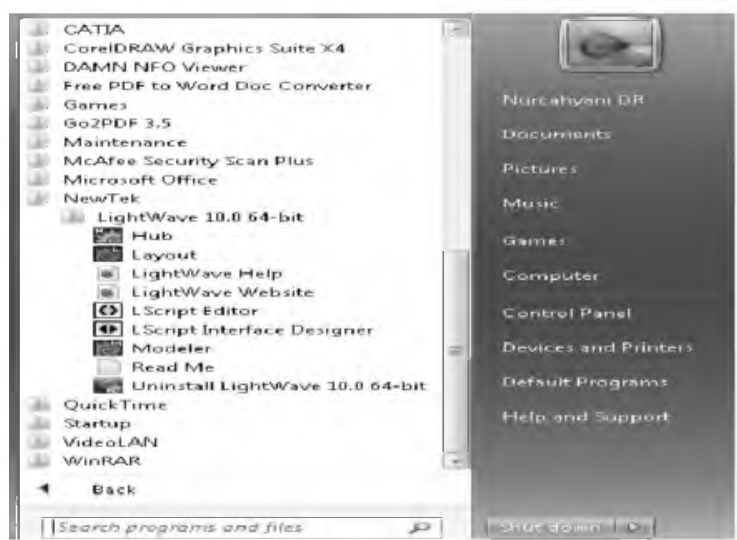

Gambar 3. Tampilan LightWave Hub, Layout dan Modeler dalam folder NewTek 


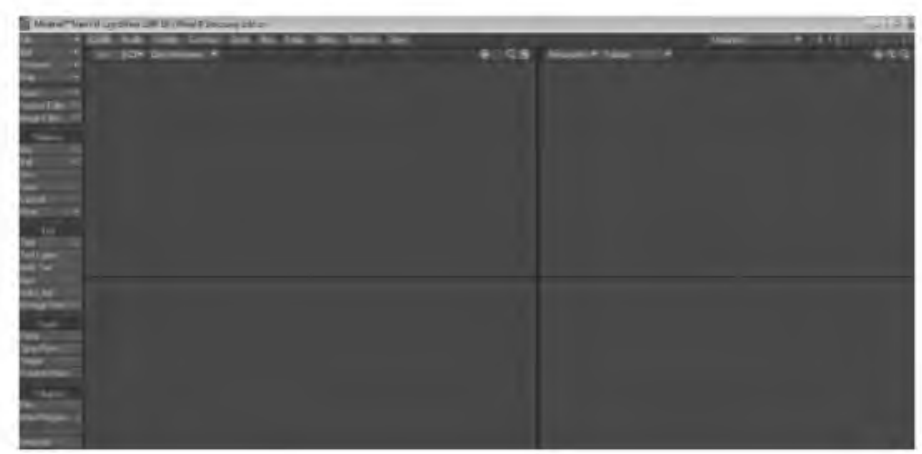

Gambar 4. Tampilan Antarmuka LightWave Modeler

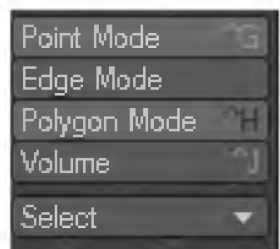

Gambar 5. Selection Polygon Mode

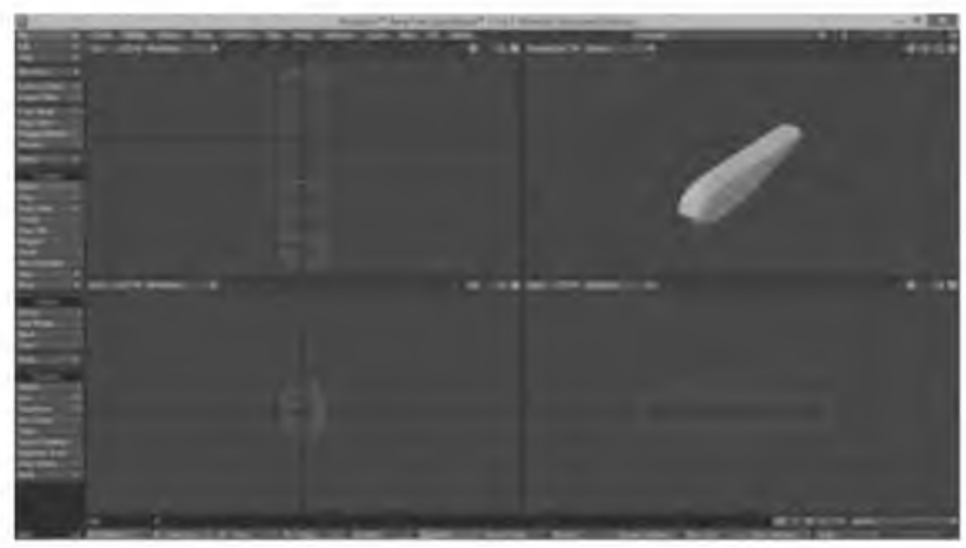

Gambar 6. Body Pesawat

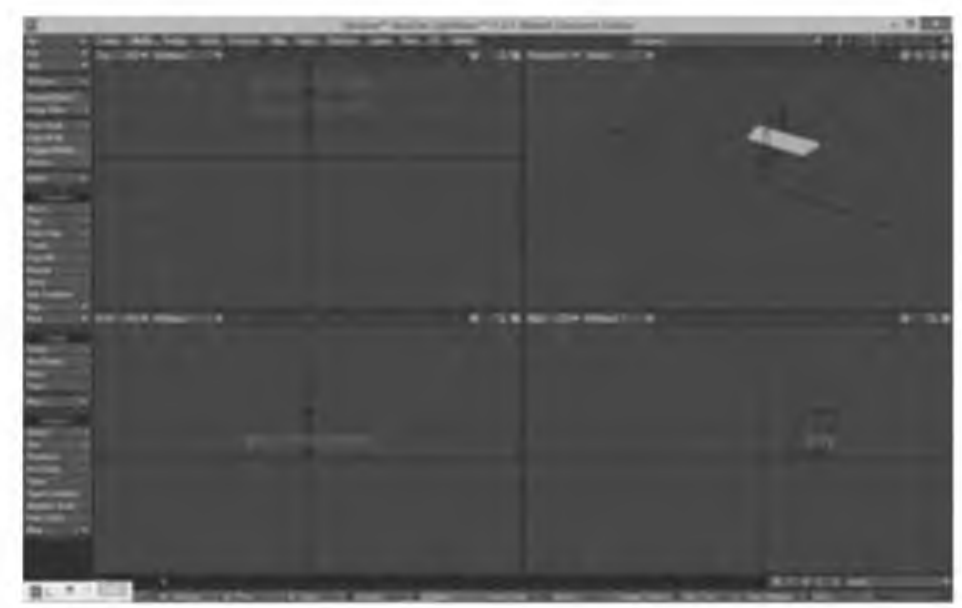

Gambar 7. Sayap Belakang Horizontal 


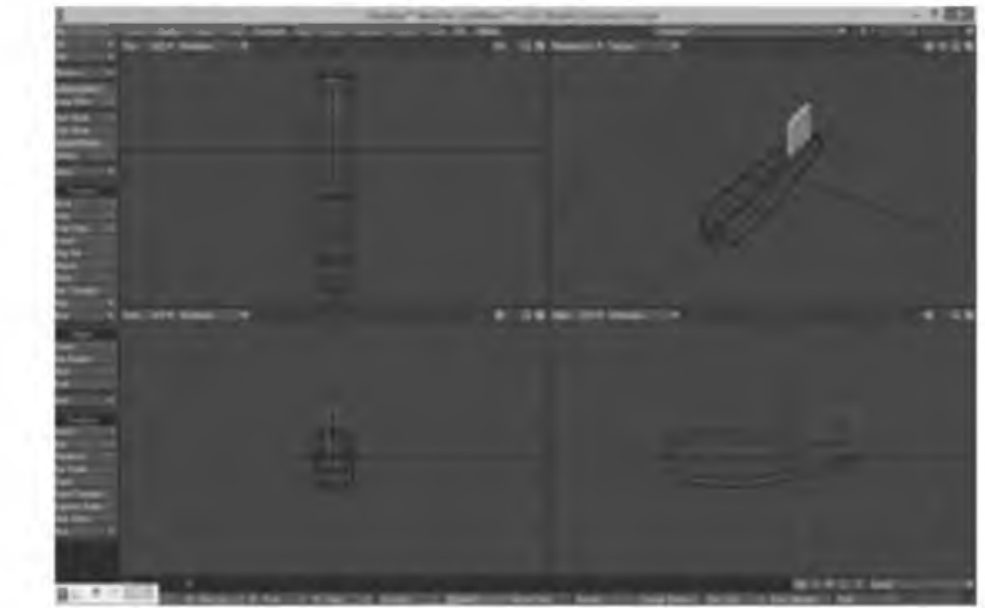

Gambar 8. Sayap Belakang Vertikal

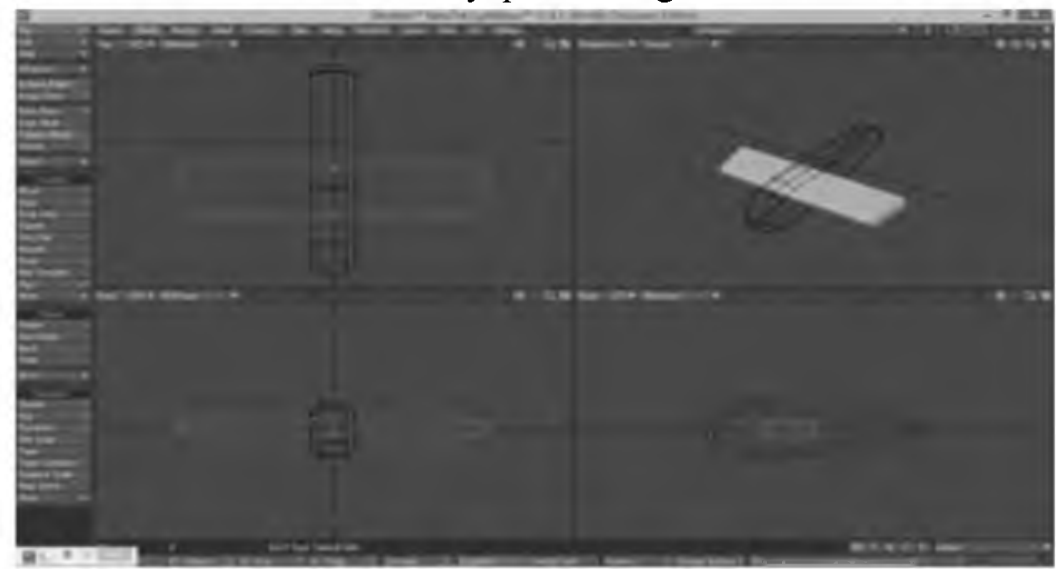

Gambar 9. Sayap depan

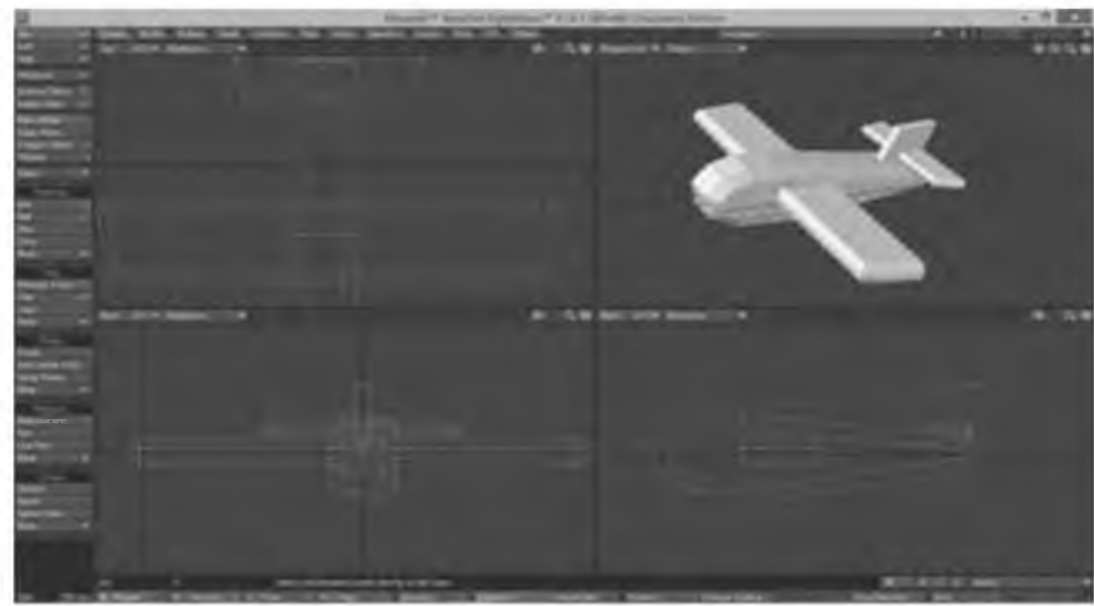

Gambar 10. Bagian-bagian pesawat yang telah disatukan

\subsection{Analisis Hasil Dengan Graphic Editor}

Hasil modelling dapat diubah pada graphic editor yang ada di LightWave Layout seperti terlihat pada Gambar 11. 


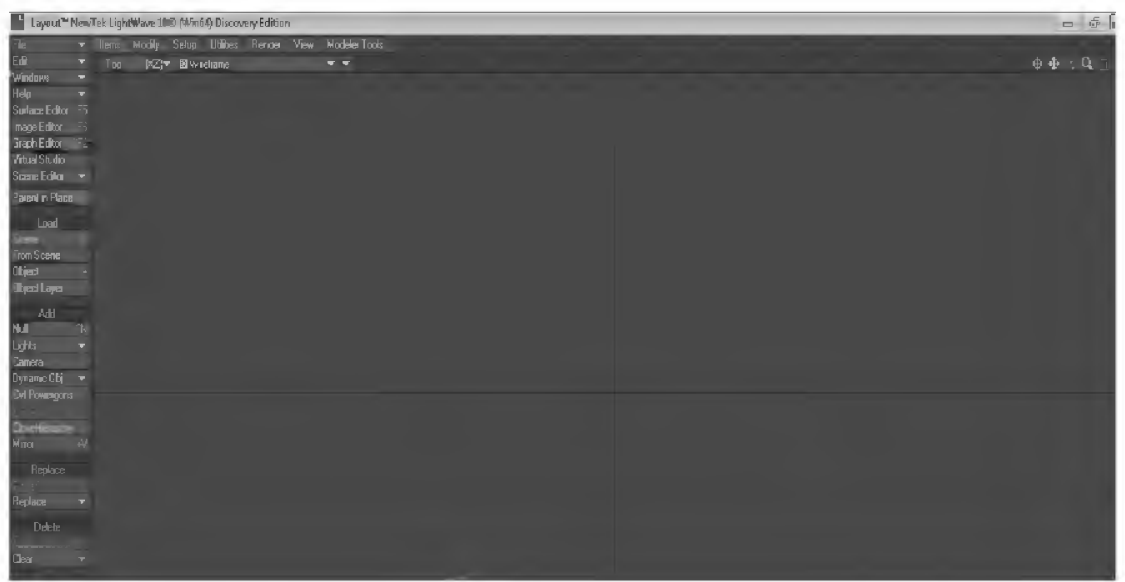

Gambar 11. Graphic Editor pada LightWave Layout

Hasil modeling pesawat pada LightWave Modeler kemudian diimpor ke dalam LightWave Layout (Gambar 12).

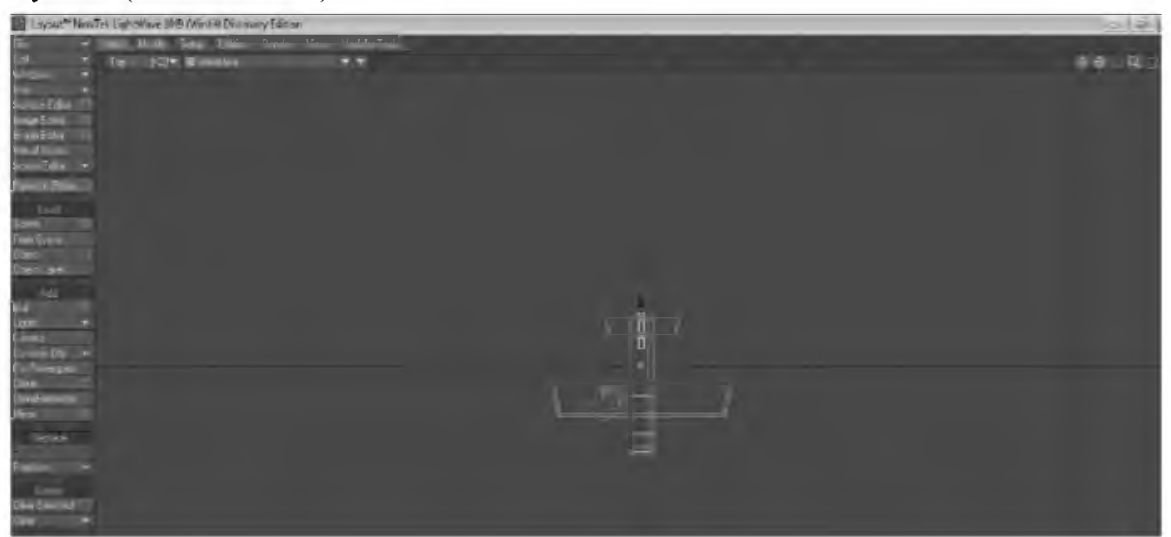

Gambar 12. Hasil modeling pesawat diimpor ke LightWave Layout

Tool graphic editor ada di sebelah kiri LightWave Layout. Modul penggunaan graphic editor dapat dilihat pada expression builder. Kemudian dilakukan analisis hasil modeling dengan menggunakan graphic editor (Gambar 13). Hasil modeling dikoreksi mumeric limit point dan diseleksi per layer. Hasil modeling yang telah dianalisis dengan graphic editor dapat dilihat pada Gambar 14.

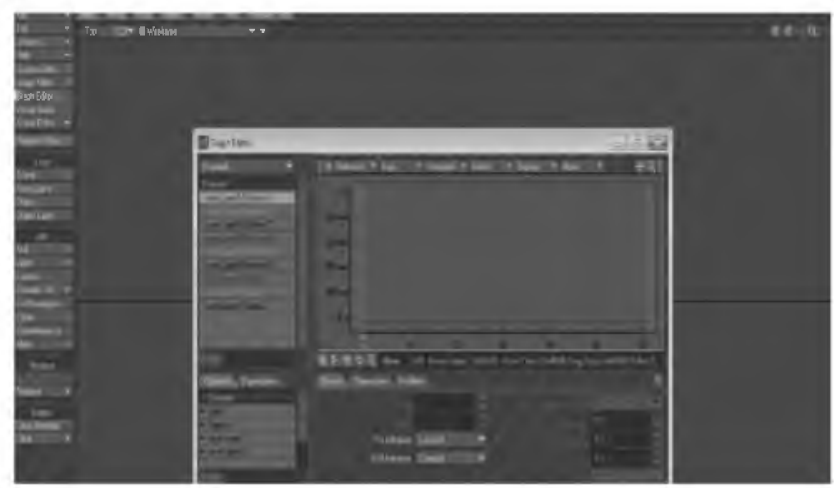

Gambar 13. Graphic editor 


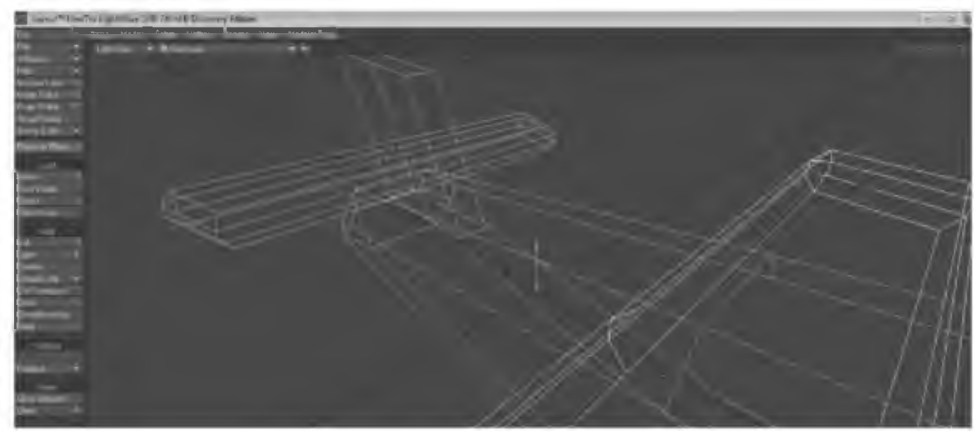

Gambar 14. Hasil analisis dengan graphic editor

\section{Kesimpulan dan Saran}

\subsection{Kesimpulan}

Penelitian dengan judul Analisis Penerapan Penggunaan Graphic Editor Pada Pembuatan Objek 3 Dimensi menghasilkan suatu kesimpulan:

1. Modeling suatu objek 3D menggunakan LightWave Modeler.

2. Hasil modeling kemudian dianalisis dengan menggunakan graphic editor pada LightWave Layout. Analisis dengan menggunakan graphic editor dapat membuat suatu pemodelan menjadi lebih baik karena penyeleksian setiap layer lebih detil daripada tidak menggunakan graphic editor.

\subsection{Saran} animasi.

Penelitian ini dapat dilanjutkan pada proses rendering objek 3D dan pembuatan scene

\section{Daftar Pustaka}

Awaluddin, T., 2005, LightWave 3D Versi 8.0. Penerbit Elex Media Komputindo. Jakarta. Awaluddin, T., Wiradinata, G., 2008, Membuat 3Dmovie dengan Lightwave 3D 8.0, Penerbit Salemba Infotek, Jakarta.

F1 Help Software LightWave 11.0

adityaakbr.blogspot.com, diakses pada tanggal 20 Juni 2015

Guerrilaz.com, diakses pada tanggal 1 Juni 2015.

Forums.newtek.com, diakses pada tanggal 20 Juni 2015. 